\title{
3D Airway changes using CBCT in patients following mandibular setback surgery \pm maxillary advancement
}

\author{
Andrew G. Havron ${ }^{1}$ | Sharon Aronovich ${ }^{2}$ | Anita V. Shelgikar ${ }^{3}$ | H. Ludia Kim ${ }^{4}$ | \\ R. Scott Conley ${ }^{5}$
}

${ }^{1}$ Department of Orthodontics and Pediatric Dentistry, University of Michigan, Ann Arbor, Michigan

${ }^{2}$ Department of Oral and Maxillofacial Surgery, University of Michigan, Ann Arbor, Michigan

${ }^{3}$ Department of Neurology, University of Michigan, Ann Arbor, Michigan

${ }^{4}$ Private Practice, Ann Arbor, Michigan

${ }^{5}$ Department of Orthodontics, University at Buffalo, Buffalo, New York

\section{Correspondence}

R. Scott Conley, University at Buffalo School of Dental Medicine, Buffalo, NY.

Email: rsconley@buffalo.edu

\begin{abstract}
Structured Abstract
Introduction: The aim of this study was to determine the 3D airway changes that occur following mandibular setback surgery alone vs bimaxillary surgery in patients with similar skeletal start forms.
\end{abstract}

Setting and Sample Population: The University of Michigan School of Dentistry and Medical Center. A total of 85 patients undergoing mandibular setback with or without simultaneous maxillary advancement.

Materials and Methods: A retrospective evaluation of pre- and post-surgical CBCT scans for patients undergoing mandibular setback surgery alone (14) vs bimaxillary surgery (71) was performed. Cross-sectional evaluation at standardized locations, minimum cross section and volumetric analysis were performed (Dolphin Imaging \& Management Solutions).

Results: Patients who underwent mandibular setback surgery alone showed a statistically significant average increase of $47.5 \mathrm{~mm}^{2}$ in minimum axial area. Patients who underwent bimaxillary surgery showed a statistically significant increase in airway volume, minimum axial area, location of minimum axial area, and axial area at the retropalatal and retroglossal regions.

Conclusions: The results demonstrate that the mandible can be setback safely without decreasing airway dimensions. In borderline OSA patients, bimaxillary surgery remains the preferred approach due to the larger airway increases observed. Longterm follow-up with polysomnography must be conducted to determine the full functional implications of both procedures.

\section{KEYWORDS}

airway remodelling, cone beam computed tomography, orthognathic surgery

\section{1 | INTRODUCTION}

Patients who seek orthodontic care have either a dental malocclusion, skeletal malocclusion, or a combination of the two. Dental malocclusions are best described as improper alignment or relationship of the teeth with properly positioned maxillary and mandibular skeletal bases. Skeletal malocclusion is best described as an improper position of the bony bases of the maxilla, the mandible, or both, with normal alignment of the teeth over the bony bases. A combined dental and skeletal malocclusion is a combination of improper alignment/relationship of the teeth along with improper position of the bony bases of the maxilla and/or mandible.

Class III skeletal malocclusion is a condition frequently seen in orthodontic practice, but is less common than Class II malocclusion. According to data from the third National Health and Nutrition Examination Survey (NHANES III), a fraction of one per cent of American adult patients present with Class III malocclusion. ${ }^{1}$ Despite this relatively small figure, a high percentage of those patients seek 
treatment due to the resulting functional and aesthetic concerns. Recent data indicate that over half of the patients presenting with skeletal Class III malocclusion will require surgical intervention. ${ }^{2}$

A Class III skeletal pattern involves a relative or absolute protrusion of the mandible compared to the maxilla. This can be due to true mandibular prognathism, true maxillary retrognathism, or a combination of the two. ${ }^{3} \mathrm{~A}$ large percentage of patients will have some degree of both mandibular prognathism and maxillary retrognathism; yet a Class III malocclusion resulting from hyperplasia of the mandible alone, or hypoplasia of the maxilla alone, is relatively rare. While on the surface Class III patients appear to have a larger-thannormal mandible, it is estimated that approximately $75 \%$ of patients diagnosed with a skeletal Class III malocclusion have maxillary retrognathism as a component of their diagnosis. ${ }^{4}$ Class III malocclusion is widely believed to have an important genetic component, and studies have found multiple genetic loci associated with Class III malocclusion. ${ }^{5-7}$ The term "Hapsburg jaw" has been used in the past as a descriptor for Class III skeletal malocclusion, named after the family dynasty which had a strong predilection for prognathic mandibles. ${ }^{8}$

Class III malocclusion can be treated by several different means depending on the diagnosis and age of the patient. During adolescence, orthopaedic growth modification such as chin cup therapy ${ }^{9}$ and reverse-pull facemask therapy ${ }^{10}$ can be considered as well as a new technique involving bone-anchored maxillary protraction plates. $^{11}$

Dental Class III can commonly be treated with full fixed appliances and elastic wear ${ }^{12}$ with or without interproximal reduction. ${ }^{13}$ Orthognathic surgery, while often thought of as a "last resort," can in fact be the only reasonable option in a case with a severe skeletal imbalance and compromised facial aesthetics.

Until the 1980s, mandibular setback using the bilateral sagittal split osteotomy (BSSO) or and intraoral vertical ramus osteotomy (IVRO) $)^{14}$ was the standard form of surgical correction. ${ }^{15}$ More recently, practice trends have shifted to maxillary advancement with or without mandibular setback in part due to concern that mandibular setback surgery, while beneficial to the facial profile and occlusion may have a negative impact on a patient's pharyngeal airway space (PAS). ${ }^{16}$ Studies have used two dimensional (2D) lateral cephalometric films pre- and post-operative radiographs of patients undergoing mandibular setback surgery to measure airway changes, and many reports suggest setback leads to a decreased PAS in the short term. ${ }^{17-33}$

While 2D lateral cephalograms are reproducible, the airway is a dynamic three-dimensional (3D) structure. Cone beam computed tomography $(\mathrm{CBCT})$ is an imaging modality that is becoming more widespread in orthodontic, and orthognathic surgery discipline because it provides an accurate 3D representation of the airway and surrounding structures while also exposing the patient to significantly less radiation than would be experienced with conventional medical computed tomography or a combination of other normal dental diagnostic imaging. ${ }^{34}$ More study is clearly needed in this area. The goal of this study was to evaluate the amount and location of airway changes resulting from mandibular setback surgery compared to bimaxillary surgery for the correction of Class III skeletal deformity. The hypothesis is that mandibular setback surgery will result in airway reduction while bimaxillary surgery will result in airway increase.

\section{2 | MATERIALS AND METHODS}

Institutional review board exemption (\#HUM00083483) was granted for this retrospective study. Inclusion criteria included adult patients with pre-operative and post-operative CBCT scans who underwent either mandibular setback alone or mandibular setback with maxillary advancement for the correction of Class III skeletal malocclusion. To account for variability in head position, only patients with consistent head posture $\left(<5^{\circ}\right)$ as assessed by measuring the craniocervical angle (N-S-Ba) were included. Chart review identified 124 Class III surgical patients; 85 patients met the inclusion criteria. The final groups included 14 mandibular setback alone and 71 two-jaw surgery patients. (Table 1 ).

All scans were obtained with an EWOO Master 3DS ${ }^{\mathrm{TM}}$ CBCT scanner (EWOO Technology USA Inc., Houston, TX). The scan parameters were $90.0 \mathrm{kV}, 3.3 \mathrm{~mA}, 20 \times 19 \mathrm{~cm}$ field of view, 15-seconds exposure time, normal quality mode, $0.2 \mathrm{~mm}$ slice thickness, and isotropic voxel size of $0.40 \mathrm{~mm}$. All CBCT scans were de-identified, labelled, and saved in DICOM format.

Pre- and post-surgical cephalograms were extracted from the CBCT for every patient. The cephalograms were digitally traced and analysed using the COGS Analysis (Dolphin Imaging \& Management Solutions, Oakdale, CA).

\section{1 | Three-dimensional analysis}

Prior to analysis, all scans were reoriented. In the coronal plane, the right and left inferior orbital borders were levelled. Sagittaly, the best fit of the zygomatic arch was levelled. Axially, the lateral walls of the orbits were aligned.

The airway volume (Figure 1) was bounded superiorly by the line extending from posterior nasal spine (PNS) to the posterior pharyngeal wall and inferiorly by a parallel line from the anteriorinferior border of $\mathrm{C} 3$ to the base of the tongue. The posterior limit was the posterior pharyngeal wall, and the anterior boundary was created by the soft palate and base of the tongue. Three seed

TABLE 1 Surgical groupings

\begin{tabular}{|llll}
\hline Group & $\begin{array}{l}\text { Type of surgical } \\
\text { procedure performed }\end{array}$ & Pre-ANOVA & Post-ANOVA \\
\hline 1 Jaw & IVRO/BSSO & 14 & 14 \\
\hline 2 Jaw & Lefort +BSSO/IVRO & 71 & 41 \\
\hline & & 85 total & 55 \\
\hline
\end{tabular}

The full group of patients who underwent the assigned procedures was collected. Prior to subgroup analysis, ANOVA was performed to establish similar start forms for the two groups yielding the final study population. 


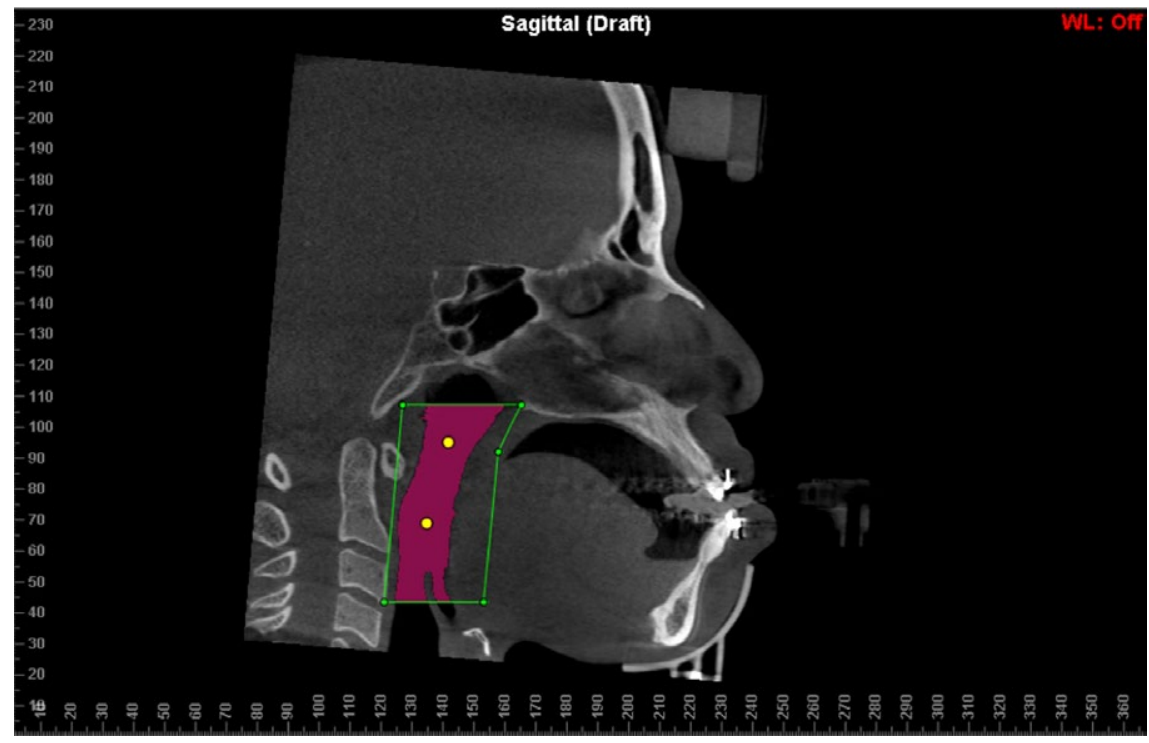

FIGURE 1 A representative CBCT airway segmentation. Mid-sagittal slice from CBCT depicting the "seed" points (yellow dots), airway region of interest (yellow box) and airway volume (purple area)

points were placed in the region of interest, and airway sensitivity was set to 73. Each scan was assessed for "bleed through" and identified areas were removed by adjusting the sensitivity and seed points.

Minimum axial airway was determined for entire airway as well as the retropalatal (anterior-inferior border of $\mathrm{C} 1$ ), retroglossal (anteriorinferior of $\mathrm{C} 2$ ) and retropharyngeal (anterior-inferior $\mathrm{C} 3$ ) regions.

\section{2 | Statistical analysis}

Paired $t$ tests were performed for 2D and 3D comparison of pre-operative to post-operative changes within groups. Welch's unpaired $t$ test was used to compare the changes pre and post surgically between the mandibular setback alone and the two-jaw surgery groups.

For intra- and inter-examiner reliability, a random number generator was used to select 10 subjects from both groups. The measurements were repeated 2 months after the initial measurements. Both intra- and inter-examiner reliability tests exhibited high correlation ranging from 0.99 to 0.987 for all measures.

\section{3 | RESULTS}

The initial sample yielded 14 mandibular setback and 71 two-jaw surgery patients. The sample was refined to establish groups with identical start forms and confirmed using ANOVA. The final sample included 14 mandibular setback and 41 two-jaw surgery patients. (Table 2).

\subsection{Cephalometric results}

The mandible was setback $6.2 \mathrm{~mm}$ in the mandibular setback alone group. Within the two-jaw surgery group, the mandible was setback a similar amount $(5.6 \mathrm{~mm})$ and the maxilla was advanced $4.5 \mathrm{~mm}$ (Table 2).

\subsection{Three-dimensional results}

Three-dimensional measurements were taken to assess several parameters of the pre- and post-operative airway, including airway volume, minimum axial area, minimum axial area distance superior to inferior border, axial area at inferior border of C1 (retropalatal) and axial area at inferior border of C2 (retroglossal). Measurement of the craniocervical angle was also recorded. The results are shown in Table 3. Mandibular setback alone patients experienced a statistically significant increase in minimum axial area. All of the other airway measures were unchanged and no airway reductions were observed. Two-jaw patients experienced statistically significant increases in airway volume, minimum axial area, vertical location of the minimum axial area, and the axial areas at both C1 (retropalatal region) and C2 (retroglossal region). The only statistically significant difference between groups was a change in axial area at the inferior border of $\mathrm{C} 1$ (or retropalatal region) only.

\section{4 | DISCUSSION}

\section{1 | Cephalometric evaluation}

Because all patients underwent orthognathic surgery, it was expected that several skeletal cephalometric measurements would show statistically significant changes consistent with the surgery performed. Patients who underwent a 1-jaw surgical procedure showed statistically significant sagittal reductions in measurements mandibular landmarks, such as B-point, pogonion and gonion. The measurements involving maxillary structures, such as Nasion to A-point, remained unchanged. The average amount of mandibular setback, based on cephalometric change, was $6.2 \mathrm{~mm}$ for the 1-jaw group.

Patients undergoing 2-jaw surgery showed statistically significant changes in measurements that involved both the maxilla and mandible. The average amount of mandibular setback, for the 2-jaw 
TABLE 2 Cephalometric pre-operative mean start forms for both 1-jaw and 2-jaw patients after subgroup creation
Comparison of 1-Jaw vs 2-Jaw cephalometric subgroups

\begin{tabular}{|c|c|c|c|}
\hline & $\begin{array}{l}\text { 1-Jaw }(n=14) \text { Pre-Op } \\
\text { Mean } \pm \text { SD }\end{array}$ & $\begin{array}{l}\text { 2-Jaw }(n=41) \text { Pre-Op } \\
\text { Mean } \pm \text { SD }\end{array}$ & $P$-value \\
\hline Ar-PTM (HP) (mm) & $32.09 \pm 2.64$ & $31.52 \pm 3.31$ & 0.6998 \\
\hline PTM-N (HP) (mm) & $55.94 \pm 3.66$ & $56.14 \pm 3.99$ & 0.7200 \\
\hline$N-A-P g\left({ }^{\circ}\right)$ & $-1.11 \pm 6.29$ & $-7.40 \pm 7.65$ & 0.0835 \\
\hline $\mathrm{N}-\mathrm{A}(\mathrm{HP})(\mathrm{mm})$ & $-1.04 \pm 3.23$ & $-2.59 \pm 4.39$ & 0.3741 \\
\hline $\mathrm{N}-\mathrm{B}(\mathrm{HP})(\mathrm{mm})$ & $-1.49 \pm 5.70$ & $0.94 \pm 9.50$ & 0.5681 \\
\hline $\mathrm{N}-\mathrm{Pg}(\mathrm{HP})(\mathrm{mm})$ & $-1.16 \pm 7.59$ & $2.90 \pm 11.39$ & 0.4532 \\
\hline N-ANS (perp HP) (mm) & $56.27 \pm 4.66$ & $56.44 \pm 4.05$ & 0.6827 \\
\hline ANS-Gn (perp HP) (mm) & $72.19 \pm 6.11$ & $77.76 \pm 8.40$ & 0.1122 \\
\hline PNS-N (perp HP) & $54.85 \pm 4.44$ & $56.65 \pm 4.39$ & 0.8689 \\
\hline Mand Plane-HP ( $\left.{ }^{\circ}\right)$ & $31.87 \pm 5.99$ & $31.20 \pm 6.67$ & 0.7443 \\
\hline U1-NF (perp NF) (mm) & $29.55 \pm 3.33$ & $30.83 \pm 4.63$ & 0.8374 \\
\hline U6-NF (perp NF) (mm) & $25.05 \pm 2.94$ & $26.72 \pm 3.25$ & 0.4089 \\
\hline L6-MP (perp MP) (mm) & $29.53 \pm 3.90$ & $31.19 \pm 3.85$ & 0.4530 \\
\hline L1-MP (perp MP) (mm) & $39.96 \pm 5.03$ & $41.08 \pm 3.73$ & 0.7756 \\
\hline PNS-ANS (HP) (mm) & $54.47 \pm 5.36$ & $55.30 \pm 4.60$ & 0.6270 \\
\hline $\begin{array}{l}\text { Ramus Height (Ar-Go) } \\
(\mathrm{mm})\end{array}$ & $54.24 \pm 5.98$ & $58.99 \pm 9.59$ & 0.3394 \\
\hline Go-Pg (mm) & $75.46 \pm 7.56$ & $76.39 \pm 10.16$ & 0.8380 \\
\hline B-Pg (MP) (mm) & $8.65 \pm 2.28$ & $10.62 \pm 2.67$ & 0.2716 \\
\hline Ar-Go-Gn (i) & $131.49 \pm 4.62$ & $131.85 \pm 6.55$ & 0.5367 \\
\hline OP-HP (i) & $9.36 \pm 5.55$ & $7.32 \pm 6.29$ & 0.3470 \\
\hline U1-NF ( $\left.{ }^{\circ}\right)$ & $118.59 \pm 7.13$ & $118.16 \pm 8.11$ & 0.6345 \\
\hline L1/Go-Me ( $\left.{ }^{\circ}\right)^{*}$ & $90.64 \pm 5.81$ & $84.46 \pm 7.44$ & $0.0157^{*}$ \\
\hline A-B (//OP) (mm) & $6.76 \pm 2.37$ & $9.69 \pm 4.99$ & 0.1817 \\
\hline
\end{tabular}

*The lower incisor to mandibular plane measurement was disregarded as this is considered a dental component.

TAB LE 3 Airway mean measurements after 2-jaw patient exclusions

\begin{tabular}{|c|c|c|c|c|c|c|c|}
\hline \multicolumn{8}{|c|}{ Comparison of similar 1-Jaw and 2-jaw patients undergoing different surgical procedures } \\
\hline $\begin{array}{l}\text { Airway volume } \\
\left(\mathrm{cm}^{3}\right)\end{array}$ & $21.47 \pm 7.36$ & $22.60 \pm 7.31$ & 1.13 & $20.45 \pm 7.89$ & $24.73 \pm 8.94$ & 4.28 & 0.0672 \\
\hline $\begin{array}{l}\text { Min. axial area } \\
\text { distance S-I (mm) }\end{array}$ & $22.00 \pm 12.52$ & $22.25 \pm 17.12$ & 0.25 & $23.88 \pm 14.41$ & $16.66 \pm 15.57$ & -7.22 & 0.2088 \\
\hline $\begin{array}{l}\text { Axial area at inf. } \\
\text { C1 }\left(\mathrm{mm}^{2}\right)\end{array}$ & $372.95 \pm 118.26$ & $397.17 \pm 129.89$ & 24.22 & $354.51 \pm 145.64$ & $427.86 \pm 138.63$ & 73.35 & $0.0472^{*}$ \\
\hline $\begin{array}{l}\text { Axial area at inf. } \\
\text { C2 }\left(\mathrm{mm}^{2}\right)\end{array}$ & $345.30 \pm 129.67$ & $384.91 \pm 141.57$ & 39.61 & $316.60 \pm 180.06$ & $369.33 \pm 156.58$ & 52.73 & 0.7428 \\
\hline
\end{tabular}

$P$-values represent a comparison of how significant of a change occurred between pre-and post-operative measurements of 1-jaw patients compared to 2-jaw patients.

${ }^{*} P<0.05$. 
group, was $5.6 \mathrm{~mm}$. The average amount of maxillary advancement for the same group was $4.5 \mathrm{~mm}$.

\section{2 | Three-dimensional evaluation}

Previous studies have suggested that mandibular setback without maxillary advancement leads to a decreased pharyngeal airway space (PAS). ${ }^{18}$ In the present investigation, the mandibular setback group showed a statistically significant increase in minimum axial area post-operatively of $47.54 \mathrm{~mm}^{2}$. The difference between investigations may result from the $2 \mathrm{D}$ vs $3 \mathrm{D}$ techniques employed. $2 \mathrm{D}$ studies are unable to visualize airway shape changes fully. A change from circular to elliptical especially if the long axis of the ellipse extends mediolaterally would not be possible to view in 2D. It was unexpected that setback surgery alone did not cause any statistically significant change at the inferior border of $\mathrm{C} 2$, the retroglossal region, which is the region most anticipated to be negatively affected.

Patients undergoing 2-jaw surgery demonstrated comprehensive statistically significant airway increases between time points. The airway volume increased by $5.31 \mathrm{~cm}^{3}$, the minimum axial area increased by $52.02 \mathrm{~mm}^{2}$, the minimum axial area distance superior to inferior border moved inferiorly by $6.07 \mathrm{~mm}$, the axial area at the inferior border of $\mathrm{C} 1$ (retropalatal region) increased by $70.49 \mathrm{~mm}^{2}$, and the axial area at the inferior border of C2 (retroglossal region) increased by $65.35 \mathrm{~mm}^{2}$. The axial area in the retropalatal region increased significantly, which should be expected due to the supporting structures being moved anteriorly. It was interesting that the minimum axial area increased, as well as the axial area in the retroglossal region. While we cannot explain exactly why this occurred, a plausible explanation could involve the anterior displacement of the maxilla, which could lead to anterior displacement of the soft palate and thus the tongue due to its contact with the soft palate. Anterior displacement of the musculature could easily cause, at least in the short term, an increase in the entire PAS. However, future work would be needed in this area to determine exactly the cause for such changes.

All patients had a bite jig used for accurate positioning in the preoperative CBCT scans. This jig props the bite open a small amount, so the results may have been affected slightly. However, all patients had the bite jig present in the pre-operative scans. In the 3D analysis, the slight opening of the bite could have theoretically led to a more compressed pre-operative airway due to the downward and backward rotation of the mandible. A subsequent study demonstrated $2 \mathrm{~mm}$ of AP reduction and $2 \mathrm{~mm}$ increased vertical displacement of pogonion but no airway changes from the splint. ${ }^{35}$

Once the final groups were refined to statistically similar starting forms, the only airway measurement which showed a statistically significant airway difference following surgery was axial area at inferior of C1-or retropalatal region. The greater airway increase makes sense, due to the different surgical techniques employed. The maxillary advancement would be expected to increase the retropalatal axial area.

Craniocervical angle change was used to assure consistent head position during their $\mathrm{CBCT}$ scan. This was essential because head angulation can cause changes in airway form (eg head tilt chin lift manoeuvre in CPR). By controlling head position, the observed differences reported can only be the result of surgery.

Based on the results of this study, fear of decreasing of patient's PAS following mandibular setback surgery alone does not appear to be warranted. However, it is possible that long-term follow-up of these patients could yield a different conclusion. The post-operative scans used in this study were taken, on average, 2 months post-surgery. A study analyzing the same patients at 1 year, 5 years, and 10 years postoperatively, for example, may yield a different result entirely.

The results of this study suggest that during treatment planning if a patient's facial appearance would benefit from a mandibular setback surgery alone there seems to be no harm in doing so. If there are signs or symptoms of OSA, surgeons may elect to perform bimaxillary surgery, or even maxillary advancement alone. A preferred approach would be to screened for OSA prior to surgery and perform PSG. If OSA is diagnosed, revision of the surgical plan with the sleep team and the orthodontist should be considered.

Retrospective studies are unable to control all variables. The results reported may not be generalizable to other surgical centres if weight, magnitude of surgery, age or gender characteristics are different.

\section{5 | CONCLUSIONS}

Based on the results of this study, fear of decreasing of patient's PAS following mandibular setback surgery alone does not appear to be warranted. Specific conclusions include:

1. Class III patients undergoing mandibular setback surgery alone showed a statistically significant increase minimum axial area of the PAS after surgery.

2. Patients who undergo bimaxillary surgery showed a significantly increased retropalatal axial area after surgery compared to patients undergoing mandibular setback alone.

3. Patients who undergo bimaxillary surgery show no other significant difference in airway volume, minimum axial area, minimum axial area location, or retroglossal axial area after surgery compared to patients undergoing mandibular setback alone.

\section{ORCID}

R. Scott Conley iD https://orcid.org/0000-0002-4888-4875

\section{REFERENCES}

1. Proffit WR, Fields HW Jr, Moray LJ. Prevalence of malocclusion and orthodontic treatment need in the United States: estimates from the NHANES III survey. Int J Adult Orthodon Orthognath Surg. 1998;13:97-106.

2. Proffit WR, Jackson TH, Turvey TA. Changes in the pattern of patients receiving surgical-orthodontic treatment. Am J Orthod Dentofacial Orthop. 2013;143:793-798. 
3. Lee JY, Kim YI, Hwang DS, Park SB. Effect of maxillary setback movement on upper airway in patients with class III skeletal deformities: cone beam computed tomographic evaluation. J Craniofac Surg. 2013;24:387-391.

4. Degerliyurt K, Ueki K, Hashiba Y, et al. A comparative CT evaluation of pharyngeal airway changes in class III patients receiving bimaxillary surgery or mandibular setback surgery. Oral Surg Oral Med Oral Pathol Oral Radiol Endod. 2008;105:495-502.

5. Yamaguchi T, Park SB, Narita A, Maki K, Inoue I. Genome-wide linkage analysis of mandibular prognathism in Korean and Japanese patients. J Dent Res. 2005;84:255-259.

6. Frazier-Bowers S, Rincon-Rodriguez R, Zhou J, Alexander K, Lange E. Evidence of linkage in a Hispanic cohort with a Class III dentofacial phenotype. J Dent Res. 2009;88:56-60.

7. Ikuno K, Kajii TS, Oka A, et al. Microsatellite genome-wide association study for mandibular prognathism. Am J Orthod Dentofacial Orthop. 2014;145:757-762.

8. Graber L, Vanarsdall R, Vig K. Orthodontics: Current Principles and Techniques, 5th edition. Philadelphia: Elsevier Mosby; 2012.

9. Chatzoudi MI, Ioannidou-Marathiotou I, Papadopoulos MA. Clinical effectiveness of chin cup treatment for the management of Class III malocclusion in pre-pubertal patients: a systematic review and meta-analysis. Prog Orthod. 2014;15:62.

10. Muthukumar K, Vijaykumar NM, Sainath MC. Management of skeletal Class III malocclusion with face mask therapy and comprehensive orthodontic treatment. Contemp Clin Dent. 2016;7:98-102.

11. Degala S, Bhanumathi M, Shivalinga BM. Orthopaedic protraction of the maxilla with miniplates: treatment of midface deficiency. $J$ Maxillofac Oral Surg. 2015;14:111-118.

12. Silveira GS, de Gauw JH, Motta AT, Mucha JN. Compensatory orthodontic treatment for maxillary deficiency: a 4-year follow-up. Am J Orthod Dentofacial Orthop. 2014;146:227-237.

13. Yezdani AA. Transparent aligners: an invisible approach to correct mild skeletal class III malocclusion. J Pharm Bioallied Sci. 2015;7:S301-S306.

14. Al-Delayme RM, Al-Khen M. Skeletal relapse after mandibular setback in bi max surgery: intraoral vertical ramus versus bilateral sagittal split osteotomies. J Maxillofac Oral Surg. 2014;13:471-477.

15. Bailey LJ, Proffit WR, White R Jr. Assessment of patients for orthognathic surgery. Semin Orthod. 1999;5:209-222.

16. Panou E, Motro M, Ates M, Acar A, Erverdi N. Dimensional changes of maxillary sinuses and pharyngeal airway in Class III patients undergoing bimaxillary orthognathic surgery. Angle Orthod. 2013;83:824-831.

17. Hong JS, Park YH, Kim YJ, Hong SM, Oh KM. Three-dimensional changes in pharyngeal airway in skeletal class III patients undergoing orthognathic surgery. J Oral Maxillofac Surg. 2011;69:e401-e408.

18. Degerliyurt K, Ueki K, Hashiba Y, et al. The effect of mandibular setback or two-jaws surgery on pharyngeal airway among different genders. Int J Oral Maxillofac Surg. 2009;38:647-652.

19. Becker OE, Avelar RL, Goelzer JG, et al. Pharyngeal airway changes in Class III patients treated with double jaw orthognathic surgerymaxillary advancement and mandibular setback. J Oral Maxillofac Surg. 2012;70:e639-e647.

20. Park SB, Kim YI, Son WS, Hwang DS, Cho BH. Cone-beam computed tomography evaluation of short- and long-term airway change and stability after orthognathic surgery in patients with Class III skeletal deformities: bimaxillary surgery and mandibular setback surgery. Int J Oral Maxillofac Surg. 2012;41:87-93.
21. Abdelrahman TE, Takahashi K, Tamura K, et al. Impact of different surgery modalities to correct class III jaw deformities on the pharyngeal airway space. J Craniofac Surg. 2011;22:1598-1601.

22. Mattos CT, Vilani GN, Sant'Anna EF, Ruellas AC, Maia LC. Effects of orthognathic surgery on oropharyngeal airway: a meta-analysis. Int J Oral Maxillofac Surg 2011;40:1347-1356.

23. Kim JS, Kim JK, Hong SC, Cho JH. Pharyngeal airway changes after sagittal split ramus osteotomy of the mandible: a comparison between genders. J Oral Maxillofac Surg. 2010;68:1802-1806.

24. Hwang S, Chung CJ, Choi YJ, Huh JK, Kim KH. Changes of hyoid, tongue and pharyngeal airway after mandibular setback surgery by intraoral vertical ramus osteotomy. Angle Orthod. 2010;80:302-308.

25. Marsan G, Cura N, Emekli U. Changes in pharyngeal (airway) morphology in Class III Turkish female patients after mandibular setback surgery. J Craniomaxillofac Surg. 2008;36:341-345.

26. Muto T, Yamazaki A, Takeda S, Sato Y. Effect of bilateral sagittal split ramus osteotomy setback on the soft palate and pharyngeal airway space. Int J Oral Maxillofac Surg. 2008;37:419-423.

27. Chen F, Terada K, Hua Y, Saito I. Effects of bimaxillary surgery and mandibular setback surgery on pharyngeal airway measurements in patients with Class III skeletal deformities. Am J Orthod Dentofacial Orthop. 2007;131:372-377.

28. Ramesh BV, Vinod N, Murugesan K. Pharyngeal airway changes following mandibular setback surgery. Indian J Dent Res. 2005;16:147-150.

29. Kawakami M, Yamamoto K, Fujimoto M, et al. Changes in tongue and hyoid positions, and posterior airway space following mandibular setback surgery. J Craniomaxillofac Surg. 2005;33:107-110.

30. Guven O, Saracoglu U. Changes in pharyngeal airway space and hyoid bone positions after body ostectomies and sagittal split ramus osteotomies. J Craniofac Surg. 2005;16:23-30.

31. Tselnik M, Pogrel MA. Assessment of the pharyngeal airway space after mandibular setback surgery. J Oral Maxillofac Surg. 2000;58:282-285.

32. Kawamata A, Fujishita M, Ariji Y, Ariji E. Three-dimensional computed tomographic evaluation of morphologic airway changes after mandibular setback osteotomy for prognathism. Oral Surg Oral Med Oral Pathol Oral Radiol Endod. 2000;89:278-287.

33. Greco JM, Frohberg U, Van Sickels JE. Long-term airway space changes after mandibular setback using bilateral sagittal split osteotomy. Int J Oral Maxillofac Surg. 1990;19:103-105.

34. Loubele M, Bogaerts R, Van Dijck E, et al. Comparison between effective radiation dose of CBCT and MSCT scanners for dentomaxillofacial applications. Eur J Radiol. 2009;71:461-468.

35. Sencak GLES, Aronovich A, Benavides E, Conley RS. In vitro and in vivo analysis of bite jig effect on mandibular and condylar displacement. J Oral Maxillofac Surg 2018. submitted.

How to cite this article: Havron AG, Aronovich S, Shelgikar AV, et al. 3D Airway changes using CBCT in patients following mandibular setback surgery \pm maxillary advancement. Orthod Craniofac Res. 2019;22(Suppl. 1):30-35. https://doi. org/10.1111/ocr.12291 